\title{
Correction: HDAC6 inhibitor WT161 downregulates growth factor receptors in breast cancer
}

\section{Teru Hideshima ${ }^{1}$, Ralph Mazitschek ${ }^{2}$, Jun $\mathbf{Q i}^{1}{ }^{1}$ Naoya Mimuraa, ${ }^{1,}$ Jen-Chieh Tseng ${ }^{3,6}$, Andrew L. Kung ${ }^{3,4,7}$, James E. Bradner ${ }^{1,8}$ and Kenneth C. Anderson ${ }^{1}$}

\footnotetext{
${ }^{1}$ Department of Medical Oncology, Dana-Farber Cancer Institute and Harvard Medical School, Boston, MA, USA

${ }^{2}$ Center for Systems Biology, Massachusetts General Hospital, Harvard Medical School, Boston, MA, USA

${ }^{3}$ Lurie Family Imaging Center, Dana-Farber Cancer Institute, Boston, MA, USA

${ }^{4}$ Department of Pediatric Oncology, Dana-Farber Cancer Institute and Children's Hospital Boston, Boston, MA, USA

${ }^{5}$ Department of Hematology, Chiba University Hospital, Chiba, Japan

${ }^{6}$ PerkinElmer Inc., Hopkinton, MA, USA

${ }^{7}$ Memorial Sloan Kettering Cancer Center, New York, NY, USA

${ }^{8}$ Novartis Institutes for BioMedical Research, Cambridge, MA, USA
}

Published: August 17, 2021

Copyright: (c) 2021 Hideshima et al. This is an open access article distributed under the terms of the Creative Commons Attribution License (CC BY 3.0), which permits unrestricted use, distribution, and reproduction in any medium, provided the original author and source are credited.

This article has been corrected: The CONFLICTS OF INTERESTS section has been updated as shown below:

\section{CONFLICTS OF INTEREST}

K.C. Anderson is on the advisory board of Celgene, Gilead, Millennium and Bristol Myers Squibb; and is a scientific founder with financial interest in Acetylon, Oncopep and C4 Therapeutics. JB is a scientific founder with financial interest in Acetylon.

Original article: Oncotarget. 2017; 8:80109-80123. https://doi.org/10.18632/oncotarget.19019 